\title{
高強度焼結鋼の疲労亀裂伝播特性
}

岩田 篤, 山口 和幸, 下山 仁一, 河合 伸泰

福井工業大学, 干 910-8505 福井市学園 3-6-1.

\section{The Characteristics of Fatigue Crack Propagation in the High Tensile Strength Sintered Steels}

\author{
Atsushi Iwata, Kazuyuki Yamaguchi, Toshikazu Shimoyama and Nobuyasu Kawai \\ Fukui University of Technology, 3-6-1 Gakuen, Fukui 910-8505.
}

Received June 12, 2003

\section{SYNOPSIS}

Fatigue crack propagation behavior was investigated for high tensile sintered steels of about 1000MPa level.

It was made clear that the diffusion bonded steel was most excellent as for the fatigue crack propagation behavior. The difference of fatigue crack propagation behavior with the different $\mathrm{Ni}$ content and sintered density was found to be significant, even if the alloying method was the same.

As for high tensile sintered steel, it was found that fatigue crack propagated through grain boundaries.

KEY WORDS

High tensile sintered steel, Fatigue crack propagation, $\mathrm{Fe}-\mathrm{Ni}-\mathrm{Mo}-(\mathrm{Cu})-\mathrm{C}$ alloys

\section{1 緒 言}

高強度焼結鋼の波労亀裂の発生と伝播を明らかにすること は機械構造部品を設計する上で, 極めて重要な問題である. また，焼結鋼の疲労強度を高めることが望まれており，この ような観点から，小型簡易型疲労試験機を使用し，鋭い切欠 き状態のCT 試験片を用いて疲労龟裂伝播特性を比較検討し た. 本研究では引張強さが $1000 \mathrm{MPa}$ 級の供試鋼として, 焼入 れ焼戻しの高強度焼結鋼である部分拡散型焼結鋼(PA-A), プ レアロイ型焼結鋼(PA-B), プレアロイープレミックス型焼結 鋼 (PA-C, PA-D, PA-F) を用いて疲労亀裂伝播特性を調べた。 また400MPa級でMnS添加方法の異なる焼結のままの低強度 焼結鋼 (PA-K, PA-M, PA-P) と比較する.

\section{2 実験方法}

\section{1 疲労亀裂伝播試験}

本装置はFig.1に示すように荷重を伀達するレバーを活用 し，A点に圧縮変位を与え，支点部 B 点を介して C 点に荷重 が伝わり，試験片に引張力を負荷する方式である．A 点の モー夕軸に取り付けた偏芯力ムを回転させて荷重を変動させ ることのできるようにした試験機で，下記のような仕様であ る.
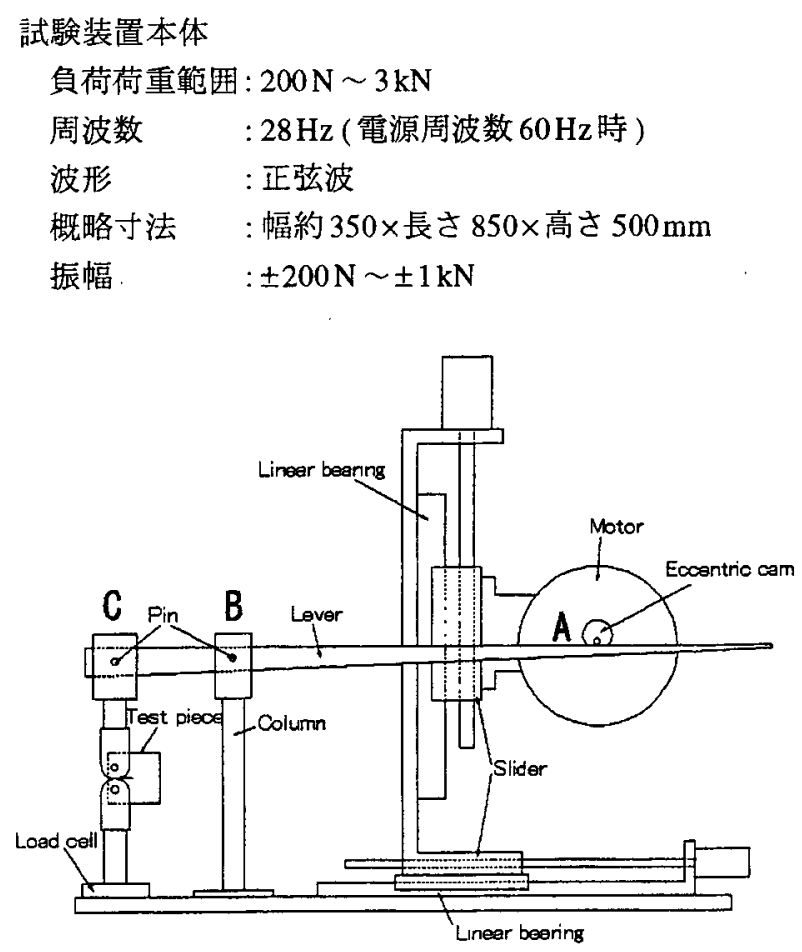

Fig.1 Fatigue Test Equipment. 
疲労刍裂伝播試験に使用したCTタイプの超小型試験片の寸 法形状を Fig.2に示す. 最大荷重 $\mathrm{P}_{\text {max }}$ を決定後, 時間と共に荷 重が随時変動があった場合には初めに決定した荷重を保つよ うに調整しながら実験を実施した，供試材料の降伏応力より 求められる $\mathrm{P}_{\max }$ の $1 / 2$ 以下を荷重条件に設定し， $\mathrm{P}_{\max }$ より $\mathrm{K}_{\max }$, $\mathrm{P}_{\operatorname{mun}}$ より $\mathrm{K}_{\operatorname{mun}}$ を求め, $\mathrm{K}_{\max }$ と $\mathrm{K}_{\operatorname{man}}$ の比を $\mathrm{R}=\mathrm{K}_{\operatorname{mur}} / \mathrm{K}_{\max }$ から求め た $^{1-3)}$. その $\mathrm{R} の$ 值は 0.1 を目標とした.

続いて, CT試験片に対して応力拡大你数範囲 $\Delta \mathrm{K}$ は次式で 計算した.

$$
\begin{aligned}
\Delta K= & \frac{\Delta P(2+\alpha)}{b(1-\alpha)^{3 / 2} \sqrt{w}} \\
& \quad\left(0.086+4.64 \alpha-13.32 \alpha^{2}+14.72 \alpha^{3}-5.6 \alpha^{4}\right) \\
& \alpha=a / w \\
& \Delta P: \text { 荷重 }(\mathrm{N}) \quad \Delta P=P_{\max }-P_{\min } \\
& a: \text { 刍裂長さ }(\mathrm{m}) \quad w: \text { 板幅 }(\mathrm{m}) \quad b: \text { 板厚 }(\mathrm{m})
\end{aligned}
$$

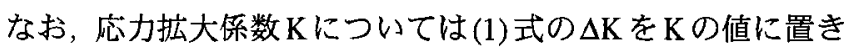
換え計算できる.

また，疲労亀裂伝播速度 $\mathrm{da} / \mathrm{dN}$ と応力拡大係数範囲 $\Delta \mathrm{K}$ は， Paris 式によって次の (2) 式で表される.

$$
\begin{aligned}
d a / d N= & C_{2}(\Delta K)^{m_{2}} \\
& \mathrm{C}_{2} \text { 及び } \mathrm{m}_{2} \text { は材料定数 }
\end{aligned}
$$

また，疲労刍裂が伝播しなくなる下限界岕力拡大保数範囲 $\Delta \mathrm{K}_{\mathrm{th}}$ から，疲労亀裂が伝播しなくなる亀裂先端の開口変位範 囲 $\Delta C \mathrm{COD}_{\mathrm{N}}$ (Crack Tip Opening Displacement) は次の (3) 式で求
められる。

$$
\begin{aligned}
\triangle C T O D_{t h} & =\frac{4\left(\Delta K_{t h}\right)^{2}}{\pi E \sigma_{y s}} \\
& \mathrm{E}: \text { ヤング率 } \quad \sigma_{\mathrm{ys}}: 0.2 \% \text { 耐力 }
\end{aligned}
$$

\begin{tabular}{|c|c|c|c|c|c|}
\hline No & Component & Base powder & Alloying method & $\begin{array}{l}\text { Sintering } \\
\text { condition }\end{array}$ & Heat treatment \\
\hline PA-A & $0.4 \mathrm{C}-4 \mathrm{Ni}-0.5 \mathrm{Mo}-1.5 \mathrm{Cu}$ & $4800 \mathrm{DF}-\mathrm{Cu}-0.5 \mathrm{C}$ & diffusion & \multirow{8}{*}{$\begin{array}{c}1140^{\circ} \mathrm{C} \\
20 \text { min } \\
\mathrm{N}_{2} \text { gas }\end{array}$} & \multirow{5}{*}{$\begin{array}{c}880^{\circ} \mathrm{C} \\
60 \mathrm{~min} \mathrm{OQ} \\
180^{\circ} \mathrm{C} \\
60 \mathrm{~min} \mathrm{AC}\end{array}$} \\
\hline PA-B & $0.4 \mathrm{C}-0.5 \mathrm{Ni}-1 \mathrm{Mo}$ & $46 \mathrm{~F} 4 \mathrm{H}-0.5 \mathrm{C}$ & prealloy & & \\
\hline $\mathrm{PA}-\mathrm{C}$ & $0.4 \mathrm{C}-2.5 \mathrm{Ni}-1 \mathrm{Mo}$ & $46 \mathrm{~F} 4 \mathrm{H}-2 \mathrm{Ni}-0.5 \mathrm{C}$ & prealloy-premix & & \\
\hline PA-D & $0.4 \mathrm{C}-4.5 \mathrm{Ni}-1 \mathrm{Mo}$ & $46 \mathrm{~F} 4 \mathrm{H}-4 \mathrm{Ni}-0.5 \mathrm{C}$ & prealloy-premix & & \\
\hline PA-F & $0.5 \mathrm{C}-1.5 \mathrm{Ni}-1.0 \mathrm{Mo}-2.0 \mathrm{Cu}$ & $46 \mathrm{~F} 3 \mathrm{H}-2 \mathrm{Cu}-0.6 \mathrm{C}$ & prealloy-premix & & \\
\hline PA-K & $0.5 \mathrm{C}-0.3 \mathrm{Mn}-0.3 \mathrm{MnS}$ & $300 \mathrm{M}-\mathrm{Mn}$ & premix & & \multirow{3}{*}{ As sintered } \\
\hline PA-M & $0.56 \mathrm{C}-0.6 \mathrm{Mn}-0.3 \mathrm{~S}$ & 400MSA & prealloy & & \\
\hline PA-P & $0.5 \mathrm{C}$ & $300 \mathrm{M}-\mathrm{Mn}$ & premix & & \\
\hline
\end{tabular}

\section{2 供試焼結鋼}

焼入れ焼戻し高強度焼結鋼(PA-A, PA-B, PA-C, PA-D, PA-F) と, 焼結のままの低強度焼結鋼(PA-K, PA-M, PA-P)の製造条 件をTable 1 に，化学組成をTable 2，機械的性質をTable 3に それぞれ示した。

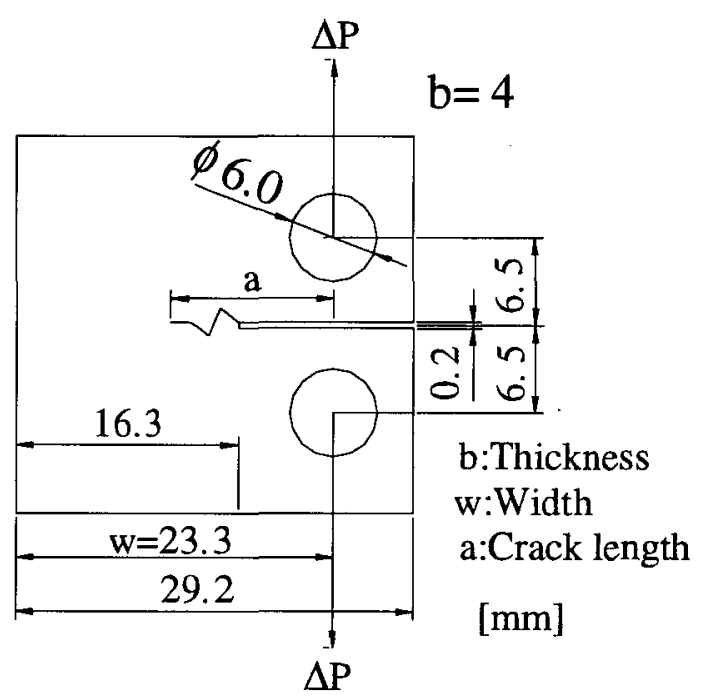

Fig.2 CT Specimen.

Table 1 Manufacturing conditions of sintered steels.

Table 2 Chemical compositions of sintered steels.

\begin{tabular}{|c|c|c|c|c|c|c|c|c|c|}
\hline \multirow{2}{*}{ No } & \multicolumn{9}{|c|}{ Chemical compositions (wt\%) } \\
\cline { 2 - 11 } & $\mathrm{C}$ & $\mathrm{Si}$ & $\mathrm{Mn}$ & $\mathrm{P}$ & $\mathrm{S}$ & $\mathrm{Ni}$ & $\mathrm{Cr}$ & $\mathrm{Mo}$ & $\mathrm{Cu}$ \\
\hline PA-A & 0.42 & 0.01 & 0.08 & 0.008 & 0.004 & 4.22 & 0.02 & 0.55 & $\mathrm{Cu}: 1.5$ \\
\hline PA-B & 0.45 & 0.02 & 0.19 & 0.013 & 0.008 & 0.5 & 0.01 & 0.95 & \\
\hline PA-C & 0.46 & 0.02 & 0.19 & 0.013 & 0.007 & 2.53 & 0.02 & 0.94 & \\
\hline PA-D & 0.45 & 0.02 & 0.19 & 0.013 & 0.008 & 4.52 & 0.02 & 0.92 & - \\
\hline PA-F & 0.56 & 0.01 & 0.19 & 0.014 & 0.007 & 1.44 & 0.01 & 1.05 & $\mathrm{Cu}: 1.98$ \\
\hline PA-K & 0.48 & 0.010 & 0.41 & 0.015 & 0.104 & - & - & - & $\mathrm{Cu}: 1.92$ \\
\hline PA-M & 0.46 & 0.014 & 0.61 & 0.015 & 0.281 & - & - & - & $\mathrm{Cu}: 1.98$ \\
\hline PA-P & 0.50 & 0.008 & 0.20 & 0.015 & 0.007 & - & - & - & $\mathrm{Cu}: 2.07$ \\
\hline
\end{tabular}


Table 3 Mechanical properties of sintered steels.

\begin{tabular}{|c|c|c|c|c|c|c|c|}
\hline No & $\begin{array}{c}\text { Sintered } \\
\text { density } \\
\left(\mathrm{Mg} / \mathrm{m}^{3}\right)\end{array}$ & $\begin{array}{c}\text { Yield strength } \\
(\mathrm{MPa})\end{array}$ & $\begin{array}{c}\text { Tensile } \\
\text { strength } \\
(\mathrm{MPa})\end{array}$ & $\begin{array}{c}\text { Elongation } \\
(\%) \\
\mathrm{GL}=2.5 \mathrm{~mm}\end{array}$ & $\mathrm{RA}(\%)$ & $\begin{array}{c}\text { Vickers hardness } \\
(10 \mathrm{kgf}) \\
※(200 \mathrm{gf})\end{array}$ & $\begin{array}{c}\text { Young's } \\
\text { modulus } \\
(\mathrm{GPa})\end{array}$ \\
\hline PA-A & 7.00 & 833 & 1046 & 1.30 & 0.90 & 325 & 138 \\
\hline PA-B & 7.01 & 968 & 1113 & 0.60 & 0.40 & 331 & 141 \\
\hline PA-C & 7.02 & 951 & 1141 & 0.70 & 0.30 & 345 & 142 \\
\hline PA-D & 7.02 & 877 & 1126 & 1.10 & 0.40 & 351 & 147 \\
\hline PA-F & 6.83 & 806 & 869 & 0.50 & 0.00 & 318 & 127 \\
\hline PA-K & 6.80 & 280 & 379 & 3.10 & 2.30 & $※ 164$ & 131 \\
\hline PA-M & 6.79 & 282 & 353 & 2.70 & 2.70 & $※ 161$ & 124 \\
\hline PA-P & 6.82 & 273 & 363 & 3.30 & 2.30 & $※ 171$ & 130 \\
\hline
\end{tabular}

\section{3 試験結果と考察}

3.1 疲労亀裂伝播試験

Fig.3に焼入れ焼戻し $1000 \mathrm{MPa}$ 級高強度焼結鋼(PA-A, PA-B, PA-C, PA-D), また比較として用いた引張強さ $1000 \mathrm{MPa}$ 級の 高張力鋼 (HT-100) も合わせてプロットした. 下限界応力㧓大 係数範囲 $\Delta \mathrm{K}_{\text {th }}$ 值は, PA-A 部分拡散型焼結鋼と $\mathrm{Ni}$ 添加量の最も 多いプレアロイープレミックス型PA-D焼結鋼の $6.6 \mathrm{MPa} \sqrt{m}$ が最も高く，つブいて Ni添加量の少ないプレアロイープレ ミックス型PA-C焼結剑の $4.4 \mathrm{MPa} \sqrt{m}$, 最も低かったのはプ レアロイ型PA-B 焼結鋼の $3.4 \mathrm{MPa} \sqrt{m}$ であった. 疲労亀裂层 播速度 $\mathrm{da} / \mathrm{dN}$ の対数值の勾配 $\mathrm{m}_{2}$ は, PA-A 焼結鋼は 4.1, PA-B

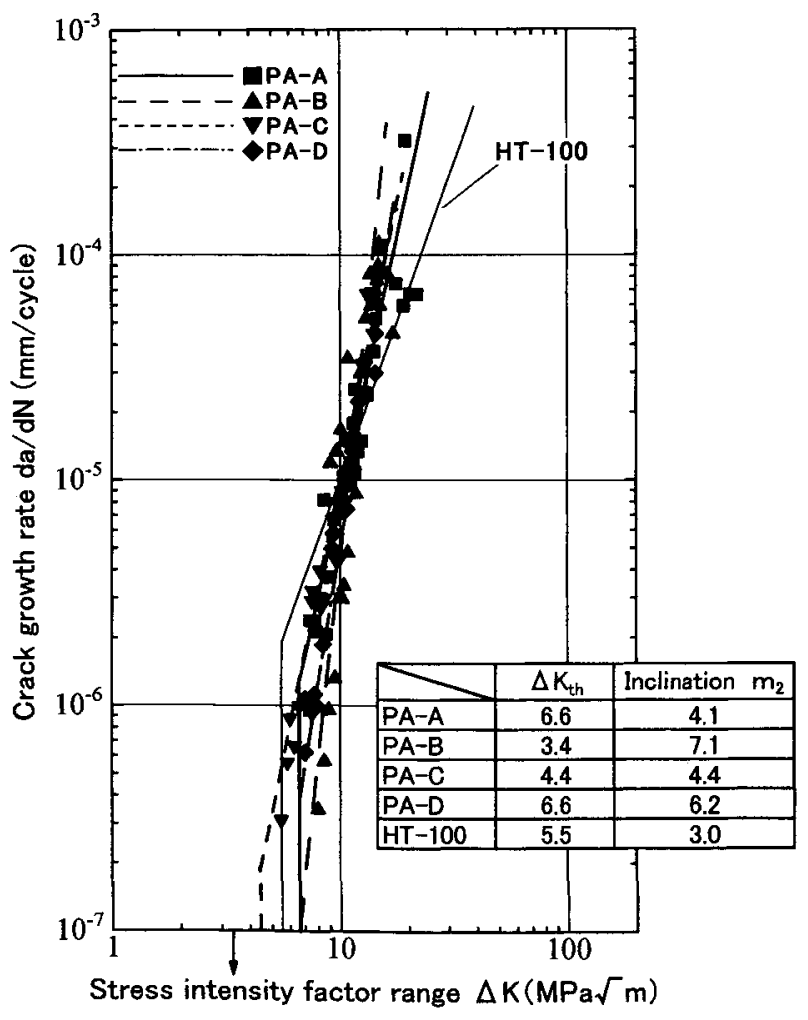

Fig.3 $\Delta \mathrm{K}-\mathrm{da} / \mathrm{dN}$ relation of PA-A, PA-B, PA-C, PA-D and HT-100.
焼結鋼は 7.1，PA-C 焼結鋼は 4.4，PA-D 焼結鋼は 6.2 が得ら れた.これらのPA-AからPA-Dまでの合金添加方法の疲労亀 裂伝播特性への影響を見ると，部分拡散型焼結鋼 PA-A が $\Delta \mathrm{K}_{\mathrm{th}}, \mathrm{m}_{2}$ ともに最も優れた伝播特性を示し，ついで $4.5 \%$ と $\mathrm{Ni}$ 添加量の多いPA-D 焼結鋼が $\Delta \mathrm{K}_{\mathrm{th}}$ は部分拡散型焼結鋼 PA-A と同じ值であったものの勾配 $\mathrm{m}_{2}$ が PA-A 焼結鋼，PA-C焼結 鋼についで 3 番目であった. プレアロイ型のPA-B 焼結龬は $\Delta \mathrm{K}_{\mathrm{th}}, \mathrm{m}_{2}$ ともに最も悪い值となった.これらの結果から金属組 織が不均質で粒界をNiなどの添加粉末で強化された部分拡散 型やプレミックス型の方が均質なプレアロイ型よりも良好な 魹裂伝播特性を持っていることが分った.また比較の高張力鋼 (HT-100)の3.0と比べると，本実験で使用した高強度焼結鋼は 勾配 $\mathrm{m}_{2}$ が大きいことから伝播速度が速いことが分かった.

つづいて PA-F 焼結鋼と PA-Pから PA-M 焼結鋼の特性を Fig.4に示す. PA-KからPA-P焼結鋼の下限界応力拡大係数範 囲 $\Delta K_{\text {th }}$ 值は，高強度焼結鋼 (PA-A, PA-B, PA-C, PA-D) の值 と比べると低い值となった．また焼結のままの低強度焼結鋼 (PA-K, PA-M, PA-P)の勾配 $\mathrm{m}_{2}$ の值は, 9.0 14.0と高い值とな 口伝播速度が速いことが分かった. 熱処理を施してあるPA-F 焼結鋼は $\Delta \mathrm{K}_{\mathrm{tn}}$ 值, 勾配 $\mathrm{m}_{2}$ の值ともに低強度焼結鋼より優れて いるが，部分拡散型焼結鋼 PA-A 焼結鋼やプレアロイープレ ミックス型PA-D 焼結鋼よりも劣っていることが分かった.

次に, 引張強さ $\sigma_{\mathrm{B}}$ と疲労刍裂が伝播しなくなる下限界応力 拡大係数範囲 $\Delta \mathrm{K}_{\mathrm{th}}$ の関係について, Fig.5に一括して示した. 高張力鋼では, 引張強さ $\sigma_{\mathrm{B}}$ が大きくなるにつれて $\Delta \mathrm{K}_{\mathrm{th}}$ が下が る傾向があるのに対して, 焼結鋼では, 約 $1000 \mathrm{MPa} て ゙ \Delta \mathrm{K}_{\mathrm{th}}$ が 最大になり，そこから引張強さ $\sigma_{\mathrm{B}}$ が大きくなるにつれて $\Delta \mathrm{K}_{\mathrm{t}}$ が下がると推測され，山型を描くような範囲であると考えら れる。これは低い引張強さのPA-K, PA-M, PA-Pは密度が $6.8 \mathrm{~kg} / \mathrm{m}^{3}$ 前後と PA-A から PA-Dの $7.0 \mathrm{~kg} / \mathrm{m}^{3}$ よりも低く, 気 孔が多いこと，熱処理されていないため基地が低強度である ことが高張力鋼の挙動と異なる理由と推測される. 低い引張 強さで密度を $7.0 \mathrm{~kg} / \mathrm{m}^{3}$ まで上げた時に, 高張力鎆と同様に引 張強さ $\sigma_{\mathrm{B}}$ が高くなれば, $\Delta \mathrm{K}_{\mathrm{th}}$ が低下するかどうか調べること は今後の課題である. 続いて，Fig.6に引張強さ $\sigma_{\mathrm{B}}$ と, 疲労刍 裂が伝播しなくなる龟裂先端の開口変位範囲 $\Delta C \mathrm{CTOD}_{\mathrm{th}}$ の関倸 


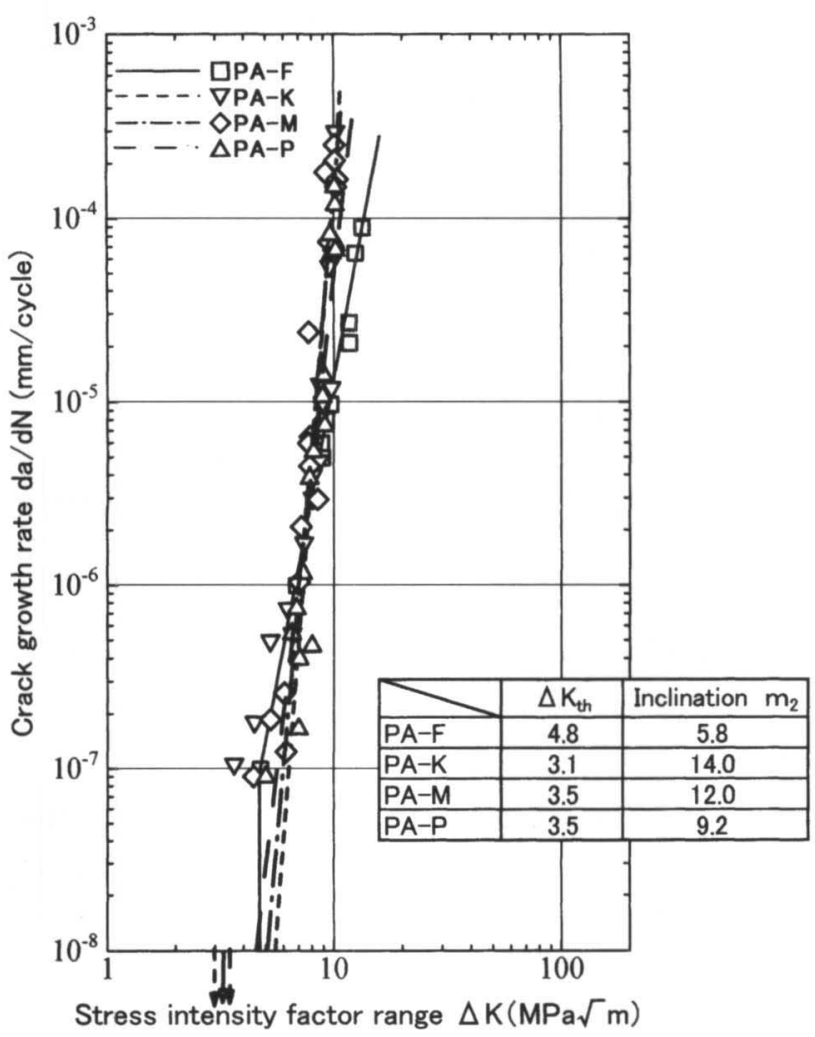

Fig.4 $\Delta \mathrm{K}-\mathrm{da} / \mathrm{dN}$ relation of PA-F, PA-K, PA-M and PA-P.

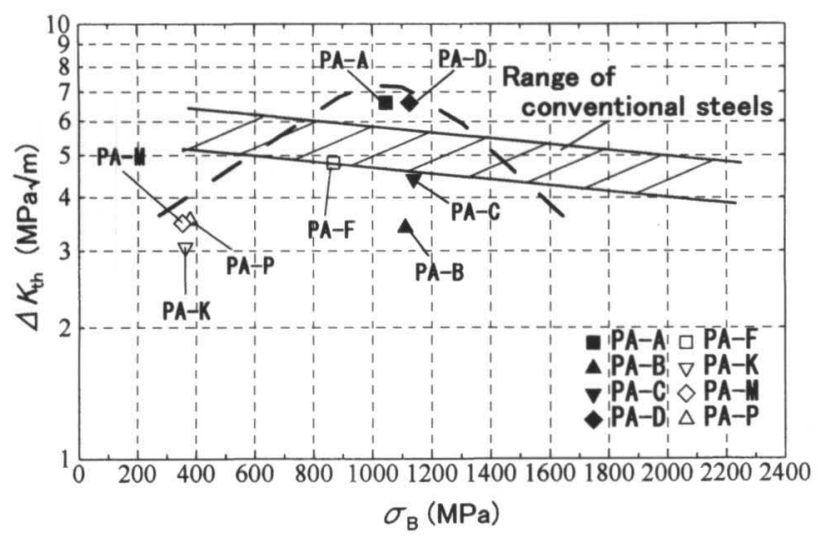

Fig.5 Relation between $\sigma_{\mathrm{B}}$ and $\Delta \mathrm{K}_{\mathrm{th}}$.

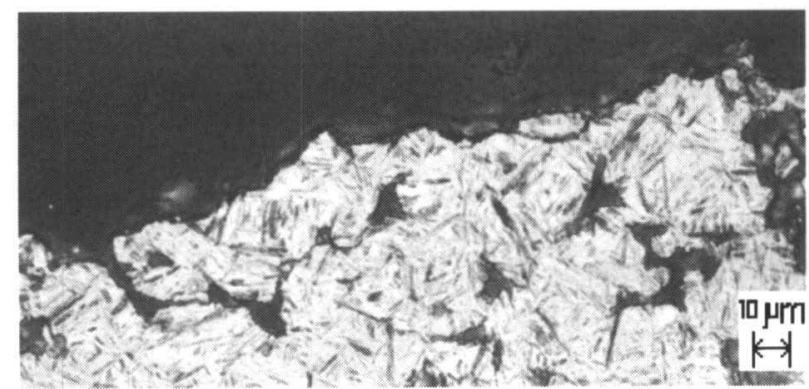

Microstructure of sintered steel (PA-B)

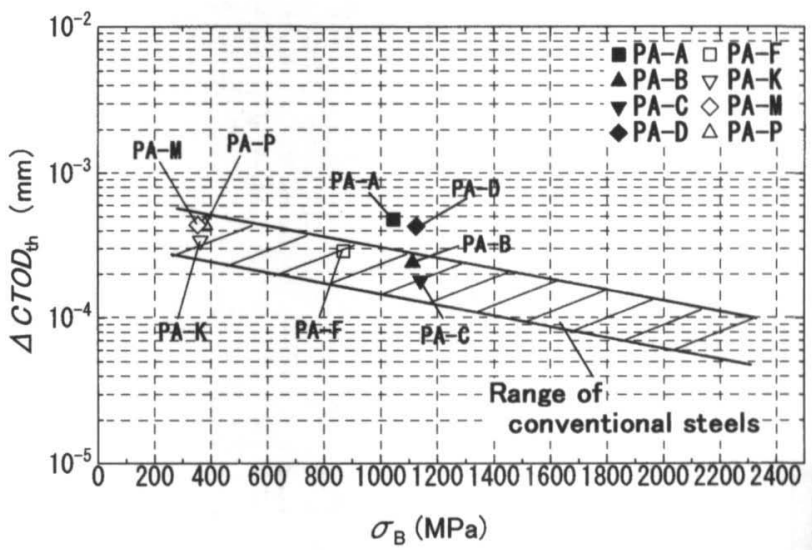

Fig.6 Relation between $\sigma_{\mathrm{B}}$ and $\Delta \mathrm{CTOD}_{\mathrm{th}}$.

を高張力鋼の実験結果と合わせて比較してみた. 高張力鋼で は, 引張強さが高くなるにつれて $\Delta \mathrm{CTOD}_{\mathrm{th}}$ が低くなるが, 今 回の供試鋼である焼結鋼もばらつきは大きいが，引張強さが 高くなるにつれ $\Delta \mathrm{CTOD}_{\mathrm{th}}$ が低くなる傾向がみられる.

\section{2 ミクロ組織観察}

高強度焼結鋼と高張力鋼についてミクロ観察を行った. Fig.7は高強度焼結鋼(PA-B)のミク口組織と高張力鋼(HT-100) のミクロ組織である. 高張力鋼は結晶粒内を通って破壊して いるのに対して, 高強度焼結鋼は, 気孔およびもとの粉末の 粒界を通っている. このことから, 粉末粒子同士の結合力が 弱く, 高強度焼結鋼は疲労によりもとの粉末の粒界を通り破 壊したと考えられる。

3.3 破断面観察

高強度焼結鋼と高張力鋼について, 走電子顕微鏡顕微鏡 (SEM)による観察を行った. Fig.8は高強度燒結鋼(PA-A) と高 張力鋼(HT-100)のSEMの写真である. 高張力鋼は疲労破面を 見ることができるが, 高強度焼結鋼では疲労破面ともとの粉 末表面を見ることができる ${ }^{4)}$.

\section{4 結 言}

引張強さが $1000 \mathrm{MPa}$ 級の, 焼入れ焼戻し高強度焼結鋼であ る, 拡散型焼結鋼 $(\mathrm{PA}-\mathrm{A})$, プレアロイ型焼結鋼 $(\mathrm{PA}-\mathrm{B})$, プレ

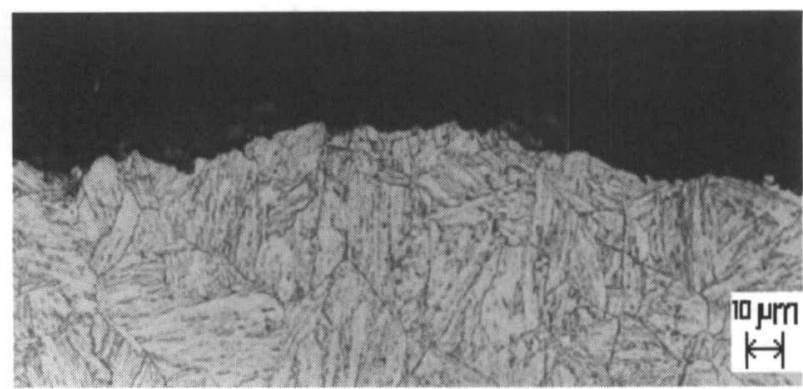

Microstructure of high tensile steel (HT-100)

Fig.7 Microstructures of sintered steel (PA-B) and high tensile steel (HT-100). 


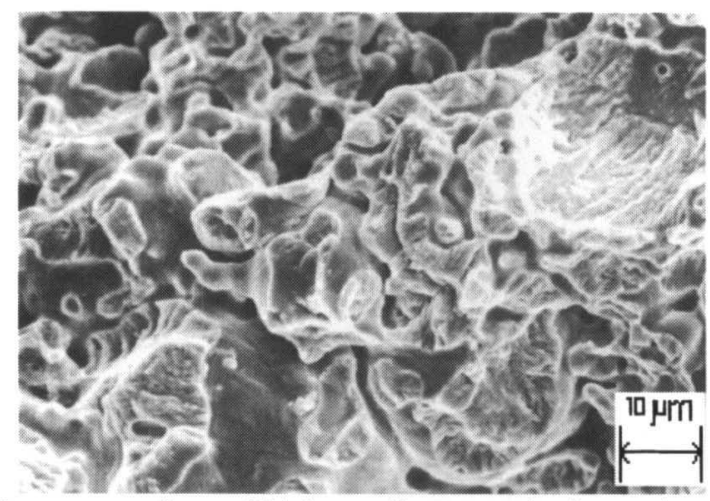

Fracture surface of high tensile strength sintered steel (PA-A)

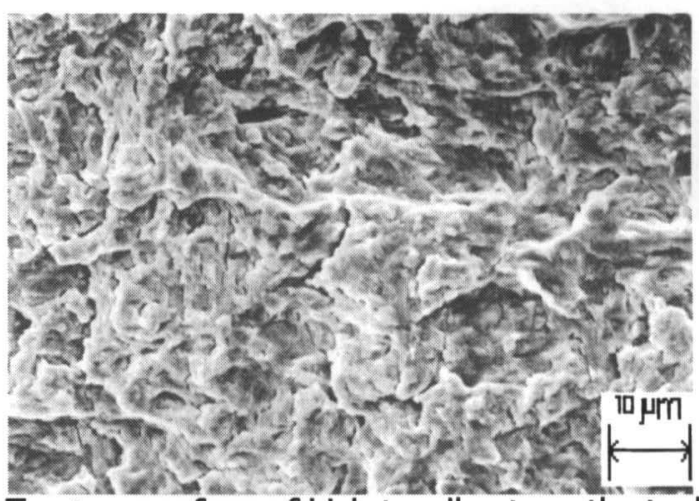

Fracture surface of high tensile strength stee

$(\mathrm{HT}-100)$

Fig.8 Fracture surface of high tensile sintered steel (PA-A)and high tensile steel (HT-100).

アロイープレミックス型焼結鋼 $(\mathrm{PA}-\mathrm{C}, \mathrm{PA}-\mathrm{D})$ について疲労亀 裂伝播特性を調ベた。

その結果を要約すると次の通りである.

(1) 高強度焼結鋼の応力拡大係数範囲 $\Delta \mathrm{K}$ と, 亀裂伝播速度 $\mathrm{da} /$ $\mathrm{dN}$ の関係を求めると, 傾き $\mathrm{m}_{2}$ はプレアロイ型焼結鋼PA$\mathrm{B}$ の值が 7.1 と最も高く伝播速度が速いことが明らかにな り, 拡散型焼結鋼PA-A の傾き $\mathrm{m}_{2}$ 值は 4.1 と高強度焼結鋼 の中では一番低い値になったことから疲労強度に最も優れ ていることが明らかになった。

(2) 高強度焼結鋼の機械的性質引張強さ $\sigma_{\mathrm{B}}$ と, 下限界応力拡 大係数範囲 $\Delta \mathrm{K}_{\mathrm{th}}$ の関係を求めると, 引張強さ $\sigma_{\mathrm{B}}$ が約 1000 $\mathrm{MPa}$ で下限界応力拡大係数範囲 $\Delta \mathrm{K}_{\mathrm{th}}$ が最大になり, そこ から引張強さ $\sigma_{\mathrm{B}}$ が高くなるにつれて下限界応力拡大係数 範囲 $\Delta \mathrm{K}_{\mathrm{th}}$ が低くなることが明らかになった。

(3) 合金元素添加方法の違いは疲労亀裂伝播特性に大きな影響
を与えるものであることが明らかになった. また化学成分 から Ni含有量が多いほど疲労亀裂特性に優れていること が分かった.

(4) 高強度焼結鋼と高強度鋼のミクロ組織から, 高張力鋼は粒 内を通り破壊しているのに対して, 高強度焼結鋼はもとの 粉末の粒界を通り破壊をしていることが明らかになった.

\section{文献}

1) 横堀武夫: 日本金属学会 強度委員会編, 金属材料の強度と 破壊, 丸善株式会社, (1964).

2) 横堀武夫 : 金属の疲労破壊, 丸善株式会社, (1970).

3) 國尾武, 中沢一, 林郁彦, 岡村弘之: 破壊力学実験法, 朝倉 書店, (1984).

4) 藤木榮 : 機械部品の疲労破壞・破断面の見方, 日刊工業新 聞社, (2002). 